\title{
Path Analysis of the Impact of "Green Finance" on Clean Energy in Yunnan Province
}

\author{
Pang Lei (first author) ${ }^{1^{*}}$, Song Ming zhe 2* $^{*}$ \\ ${ }^{1}$ School of Economics and Management, Yunnan Normal University, Kunming, Yunnan,650500, China \\ ${ }^{2}$ School of Economics and Management, Yunnan Normal University, Kunming, Yunnan,650500, China
}

\begin{abstract}
During the Two Sessions of 2018, Ruan Chengfa, the governor of Yunnan Province, proposed for the first time in the "Government Work Report" that the future development of Yunnan Province should rely on carrying out the "three green cards" strategic plan, in which the development of clean energy has obvious advantages in Yunnan Province. This paper aims to present the challenges and opportunities encountered in the development of major clean energy projects in our province, and to analyze the main impact of various forms of green capital injection on the clean energy sector by statistical analysis with reference to the index data in the "Statistical Yearbook of Yunnan Province" from the different investment perspectives of policy finance and commercial finance under "Green Finance". In view of the current situation of clean energy development in our province, this paper puts forward relevant recommendations to provide a reference for government sectors, financial sectors, enterprises and other relevant subjects in Yunnan Province at the initial stage of formulating policy routes, so as to make timely adjustments to the problems in the development process to promote the development of "Green Finance" and "three green cards" strategic plan in Yunnan Province.
\end{abstract}

\section{Introduction}

Green energy can be divided into upstream industry and downstream industry. The upstream industry mainly includes clean energy such as hydropower, natural gas, solar energy, etc.; the downstream industry mainly includes new energy vehicles, etc[1]. In view of the long investment cycle, long payback period and high investment risk of the energy sector, while considering the low investment willingness of commercial financial capital[2-3], this paper focuses on the analysis of how the policy financial capital can play a more efficient and accurate constructive role, so as to provide a reference for the investment planning of the government, and finally realize the goal that the energy of Yunnan Province can provide the province and even the whole country with more abundant clean energy on the basis of achieving green ecological development, so that it can be integrated into the national layout of "Lucid waters and lush mountains are invaluable assets"[4]. Based on the actual development of clean energy in Yunnan Province, this paper analyzes the specific function path of "Green Finance" and considers how the traditional financial instruments "Green Credit, Green Bonds and Green Stocks" to promote the development of clean energy industry in Yunnan Province, coupled with the statistical analysis using large amounts of data at the end of the article, to provide more meaningful reference for the development path of governments, production enterprises and financial institutions. This paper attempts to organically combine "Green Finance" with the unique clean energy development strategy of Yunnan Province. First of all, we need to find out what problems are encountered in the current development of clean energy in Yunnan Province, so that the role of "Green Finance" can be presented in a more concrete way. Therefore, governments, financial institutions and production enterprises in Yunnan Province can formulate development routes in a more timely, efficient and accurate manner, which will promote the development of Yunnan Province's economy in the direction of high quality, high vitality, coordination and sustainability, and provide important references for deepening the reform of electricity system, expanding the power market inside and outside the province, promoting the reform of natural gas system, promoting the transformation and upgrading of the energy equipment manufacturing industry, promoting the development of energy production and living services and accelerating energy technology innovation, thus promoting the high-quality economic development of Yunnan Province.

*Corresponding author's e-mail: panglei719@126.com 


\section{Development status and trend of the three major clean energy in Yunnan Province}

\subsection{Development status and trend of the hydropower energy in Yunnan Province}

Yunnan, by virtue of its special geographic and hydrological location, has been a province extremely rich in hydropower resources in our country for a long time. More than $80 \%$ of Yunnan Province's hydro energy resources are hidden in the water system of the Jinshan River, Lancang River and Nujiang River[5]. The steady and orderly development of hydropower resources in Yunnan is not only an important part of the implementation of the national energy strategy, but also the need to promote the economic and social development of Yunnan. According to the "2018 Statistical Yearbook of Yunnan Province" released by the Bureau of Statistics in Yunnan Province, the province's production data of major industrial products shows that the total cumulative power generation in Yunnan Province in 2018 was 30,772 million $\mathrm{kWh}$, of which the total amount of hydroelectric power generation reached 247,780 million $\mathrm{kWh}$, accounting for about 82.4 percent of the total power generation[6-8]. In 2018 , the province's hydropower energy consumption of industrial enterprises was 102,012 million $\mathrm{kWh}$. Since the 18th National Congress of the Communist Party of China, a new round of electric power system reform with marketoriented reform as the core has been fully launched[9-10]. Major breakthroughs have been made in key areas and links such as the establishment of trading centers, the liberalization plan of power consumption, and the construction of market system. The data of industrial added value of electric power production and supply industry in Yunnan from 2013 to 2018 are as follows. According to the analysis of the following table, it can be concluded that the industrial added value of the power sector in Yunnan Province shows an increasing trend year by year, and it has maintained a high growth rate in recent two years.

Table 1. Industrial added value of electric power production.

\begin{tabular}{l|l|l}
\hline Year & $\begin{array}{l}\text { Industrial Added } \\
\text { Value }\end{array}$ & $\begin{array}{l}\text { Increase Rate over } \\
\text { Last Year (\%) }\end{array}$ \\
\hline 2013 & 425.32 & 23.6 \\
\hline 2014 & 509.68 & 17.2 \\
\hline 2015 & 535.76 & 7.9 \\
\hline 2016 & 615.90 & 5.2 \\
\hline 2017 & 661.39 & 19.6 \\
\hline 2018 & - & 18.3 \\
\hline
\end{tabular}

Source: Statistical Yearbook of Yunnan Province

At the press conference on the "40th Anniversary of Electric Power Reform and Development in Yunnan" held in Kunming in October 2018, it was learned that Yunnan Province is currently carrying out a "green energy card" in the "three green cards" strategic plan. By the end of 2020, the energy industry based on electricity will have an added value of more than 140 billion yuan, surpassing the tobacco industry to become the largest pillar industry in the province. At that time, Yunnan Province will become an important west-to-east power transmission base and green energy base in the country, and it will be connected with overseas power sectors in other countries such as Southeast Asian countries.

\subsection{Development status and trend of the natural gas energy in Yunnan Province}

According to the relevant statistics of the National Energy Administration, in the past three years, the proportion of natural gas download volume in Yunnan Province in the transmission volume of China-Myanmar gas pipeline has rapidly increased from $3.16 \%$ to $26.74 \%$, and the number of commercial and residential users of pipeline natural gas has grown to 2.2 million, and Kunming City has fully completed the replacement project of natural gas, with an average annual consumption of 820 million cubic meters, accounting for $67 \%$ of the total gas consumption in the province. According to the "Annual Briefing on Oil and Gas Supply and Demand of 2018 in Yunnan Province" issued by the Yunnan Regulatory Office of the National Energy Administration, the total supply of natural gas in Yunnan Province included in the statistics in 2018 was 104.455 million cubic meters, an increase of $77.08 \%$ yearon-year. The following table shows the added value of gas production and supply industry in Yunnan Province from 2013 to 2018.

Table 2. Industrial added value of gas power production.

\begin{tabular}{c|c|c}
\hline Year & $\begin{array}{c}\text { Industrial Added } \\
\text { Value }\end{array}$ & $\begin{array}{c}\text { Increase Rate over } \\
\text { Last Year (\%) }\end{array}$ \\
\hline 2013 & 7.75 & -0.9 \\
\hline 2014 & 9.22 & -2.2 \\
\hline 2015 & 13.27 & -3.4 \\
\hline 2016 & 22.64 & -3.7 \\
\hline 2017 & 50.14 & 24.3 \\
\hline 2018 & - & 17 \\
\hline
\end{tabular}

Source: Statistical Yearbook of Yunnan Province

In March 2019, the Development and Reform Commission of Yunnan Province issued the "Opinions on the Implementation on Promoting the Coordinated and Stable Development of Natural Gas of the Yunnan Provincial People's Government", pointing out that, by the end of 2020, a backbone gas transmission network should be established to connect 11 central cities, with annual gas consumption reaching 3.2 billion cubic meters. The rate of gasification of residents in Yunnan and central city groups will reach $80 \%$, municipal central cities will reach $60 \%$, and general county central cities will reach $40 \%$, forming a gas supply and consumption pattern with strong guarantee of people's livelihood and basic balance of supply and demand. And on the premise of the coordination and stability of natural gas production, supply, marketing and storage, we will steadily accelerate the large-scale and efficient use of natural gas. By 2025, the province's natural gas consumption will reach 4 billion cubic meters, accounting for about $3 \%$ of the province's primary energy consumption, and a gas supply and consumption pattern of industrialization base and multi- 
level gas storage system, multi-source guarantee and balanced supply and demand will be formed.

\subsection{Development status and trend of the solar energy in Yunnan Province}

Relying on its unique geographical location, Yunnan Province has an annual average of 2200 hours of sunshine and a total annual solar radiation of $3615.7-6667.1 \mathrm{MJ} / \mathrm{m}^{2}$. In addition, 94\% of the region of Yunnan Province is plateau mountainous area, with 95 county areas with an average sunshine hours of more than 2000 hours, accounting for $74.6 \%$ of the total; areas with an average annual solar radiation of more than $5000 \mathrm{MJ} / \mathrm{m}^{2}$ account for more than $90 \%$ of the total area of the province, so Yunnan has sufficient market conditions to develop the solar energy industry. In 2016, the Energy Bureau of Yunnan Province promulgated the "Guidance of Promoting the Development and Utilization of Photovoltaic", which emphasized the principle of combining centralized development and distributed utilization to promote the diversified use of solar photovoltaic, thus building a silicon-based photovoltaic industry processing and manufacturing radiation base for Southeast Asia, so as to scientifically grasping the new situation of solar photovoltaic development and utilization, and effectively and steadily promote the development and utilization of photovoltaic power generation. Yunnan Province, as one of the earliest provinces to develop and utilize solar energy, has a certain degree of government policy support, scientific research basis, market demand and industrial basis.

At present, the solar energy industry in Yunnan Province is in a state of low-end overcapacity. Currently, 100 solar energy enterprises active in the market are mainly competing on the domestic solar water heating system. Most of them are small-scale enterprises with relatively slow development, which are in a passive state in the domestic industry.

\section{Statistical analysis of the impact of "Green Finance" on clean energy development in Yunnan Province}

With reference to the "Summary Table of Green Credit Statistics of 21 Major Domestic Banks (2013-2017)" published by the China Banking Regulatory Commission (CBRC) in 2018, and combined with the relevant financial data of the Kunming Central Branch of the People's Bank of China and the statistics in the "Annual Social
Responsibility Report on Banking in Yunnan Province" published by the Yunnan Banking Association, the author uses the indicator "the loan balance of energy saving and environmental protection projects and service issued by banking financial institutions in Yunnan Province" as an approximation to replace the statistical indicator of "Green Finance" in Yunnan Province, and then uses statistical analysis to analyze and describe the effects and efficiency of "Green Finance" on the clean energy industry in Yunnan Province in recent years.

According to the "Statistical Yearbook of Yunnan Province", the following two charts show the loan balance of financial institutions in Yunnan Province and the loan balance of energy saving and environmental protection industry service issued by financial institutions in Yunnan Province in corresponding years from 2014 to 2018 and the histogram of the above two (unit: 100 million yuan).

Table 3. Statistical analysis of loan balance in Yunnan Province.

\begin{tabular}{c|c|c}
\hline Year & $\begin{array}{c}\text { Loan balance of } \\
\text { financial } \\
\text { Institutions }\end{array}$ & $\begin{array}{c}\text { Banking financial } \\
\text { institutions issue loans } \\
\text { for energy conservation } \\
\text { and environmental } \\
\text { protection industry }\end{array}$ \\
\hline 2014 & 17978.74 & 1982.58 \\
\hline 2015 & 20842.86 & 2292.74 \\
\hline 2016 & 23056.28 & 2771.45 \\
\hline 2017 & 25398.93 & 3325.74 \\
\hline 2018 & 28042.02 & 3300.50 \\
\hline
\end{tabular}

Source: Statistical Yearbook of Yunnan Province

From the above table, it can be seen that the loan balance issued by the banking financial institutions in Yunnan Province for energy saving and environmental protection industry services shows an increasing trend.

At the same time, because the "Statistical Yearbook of Yunnan Province" lacks the data on the added value of clean energy industry in Yunnan Province in 2018, the article only analyzes the correlation between the three important indicators from 2014 to 2017: the industrial added value in the power sector, the added value of gas production and supply industry, and the loan balance of energy saving and environmental protection projects and service issued by banking financial institutions in Yunnan Province (Unit: 100 million yuan).

Table 4 Trends in the industrial added value in the power sector, the added value of gas production and supply industry, and the loan balance of energy saving and environmental protection projects and service issued by banking financial institutions in Yunnan Province from 2014 to 2017. 
Table 4. Development trend of three indicators of clean energy.

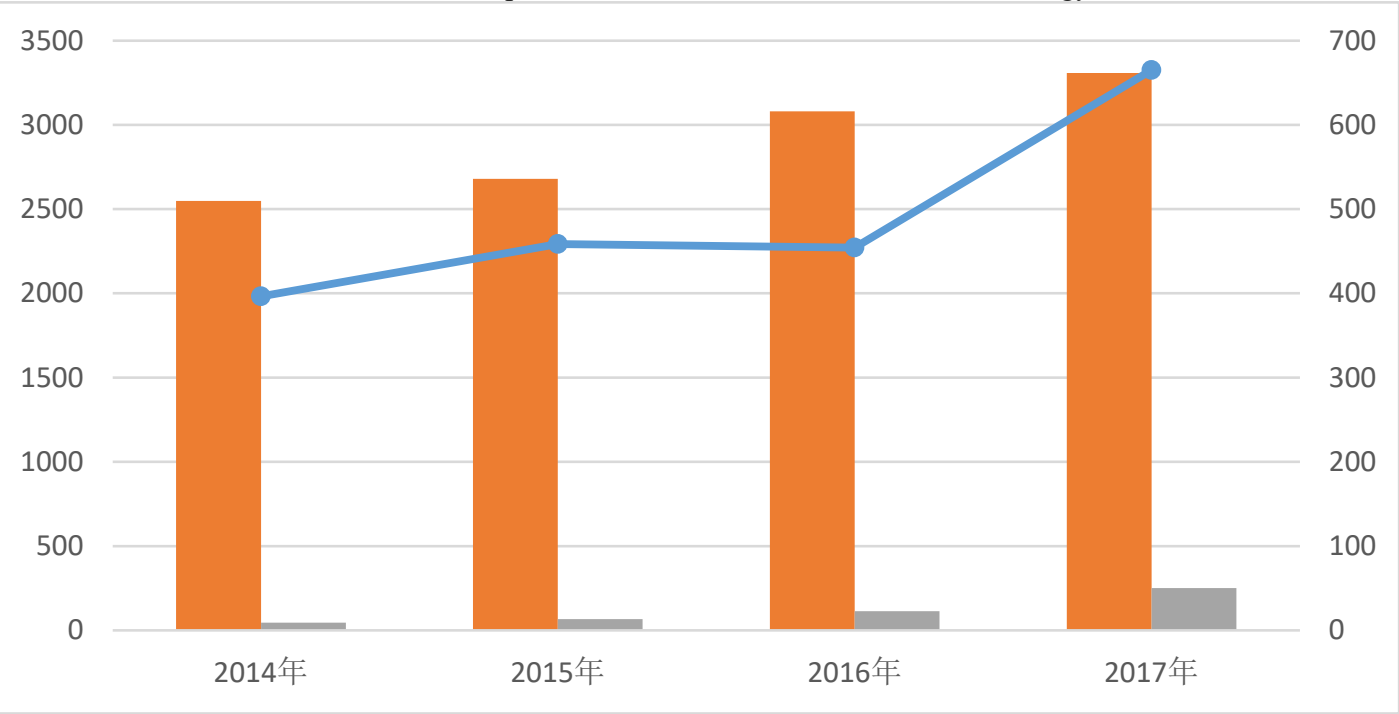

Source: Statistical Yearbook of Yunnan Province

From the data and trends shown in the above chart, we can see that from 2014 to 2017, the loans of energy saving and environmental protection projects and service issued by banking financial institutions in Yunnan Province show an increasing trend year by year, among which, in 2018 , the indicator was slightly lower than in 2017, but the overall trend still maintains a steady growth. According to the analysis of the above data, the loan balance of energy saving and environmental protection projects and service issued by banking financial institutions in Yunnan Province has increased at an average annual rate of about $11 \%$ in recent years, and by the end of 2018 , it has exceeded the 330.05 billion yuan. According to the trend chart, it can be seen that with the steady increase of the loan balance of energy saving and environmental protection projects and service issued by banking financial institutions in Yunnan Province, the added value of the clean energy industry in Yunnan Province has also shown an increasing trend year by year, which indicates that "Green Finance" with "Green Credit" of the banking financial institutions in Yunnan Province as the capital has played its role reasonably and promoted the virtuous circle development of the clean energy industry in Yunnan Province.

In order to make more accurate statistical analysis, the author uses SPSS to analyze the above three indicators. The indicator of "the loan balance of energy saving and environmental protection projects and service issued by banking financial institutions in Yunnan Province" is set as "Bank", the indicator of "the industrial added value in the power sector in Yunnan Province" is set as "Energy", and finally "the added value of gas production and supply industry in Yunnan Province" is set as "Gas". The correlation coefficient matrix and significance test pvalues (the confidence coefficient of $90 \%$ ) are adopted for analysis and the results are as follows.

Correlation coefficients of the industrial added value in the power sector, the added value of gas production and supply industry, and the loan balance of energy saving and environmental protection projects and service issued by banking financial institutions in Yunnan Province from
2014 to 2017.

Table 5. Industrial added value in the power sector Correlation matrix

\begin{tabular}{l|l|l|l}
\hline & Bank & Energy & Gas \\
\hline Bank & 1.00 & 0.84 & 0.97 \\
\hline Energy & 0.84 & 1.00 & 0.93 \\
\hline Gas & 0.97 & 0.93 & 1.00 \\
\hline
\end{tabular}

P-value of the industrial added value in the power sector, the added value of gas production and supply industry, and the loan balance of energy saving and environmental protection projects and service issued by banking financial institutions in Yunnan Province from 2014 to 2017

$\mathrm{P}$-values test results $(\mathrm{P}<0.1$ indicates a significant correlation between the two):

Table 6. Industrial added value in the power sector for P-value

\begin{tabular}{l|l|l|l}
\hline & Bank & Energy & Gas \\
\hline Bank & 0.00 & 0.16 & 0.03 \\
\hline Energy & 0.16 & 0.00 & 0.07 \\
\hline Gas & 0.03 & 0.07 & 0.00 \\
\hline
\end{tabular}

In addition to autocorrelation, as can be seen from the above table, the correlation coefficient between "the loan balance of energy saving and environmental protection projects and service issued by banking financial institutions in Yunnan Province" and "the industrial added value in the power sector in Yunnan Province" and " the added value of gas production and supply industry in Yunnan Province" is $84 \%$ and $97 \%$ in recent years, and it obviously passes the significance test. Therefore, it can be considered that there is a significant positive correlation between "Green Credit and Green Financial Capital" represented by the loan balance of energy saving and environmental protection projects and service issued by banking financial institutions and the clean energy represented by the hydropower and natural gas, i.e., "Green Finance" has a good promotion effect on the development of clean energy industry in Yunnan Province. 


\section{Suggestion}

First, "Green Credit" should support the development of clean energy in our province, optimize credit rating standards, and support technology research and development of enterprises; second, "Green Bonds" should promote the development of the clean energy industry, with government bonds and corporate bonds being issued in parallel to promote the green and highquality development of energy industry; third, "Green Stocks" should drive the green development of clean energy industry, with leading enterprises to integrate resources to issue "clean energy concept stocks".

\section{References}

1. Jiandong Chen,Bo Wang,Shuo Huang,Malin Song. The influence of increased population density in China on air pollution[J]. Science of the Total Environment,2020,735.

2. Muhammad Khalid Anser,Zahid Yousaf,Khalid Zaman,Abdelmohsen A. Nassani,Saad M. Alotaibi,Hanifah Jambari,Aqeel Khan,Ahmad Kabbani. Determination of resource curse hypothesis in mediation of financial development and clean energy sources: Go-for-green resource policies[J]. Resources Policy,2020,66.

3. Tausif Ali,Yie-Ru Chiu,Kamaleddin Aghaloo,Ahmed Jaudat Nahian,Hongzhong Ma. Prioritizing the existing power generation technologies in Bangladesh's clean energy scheme using a hybrid multi-criteria decision making model[J]. Journal of Cleaner Production,2020,267.

4. Hui-min Mu,Hong-Xia Yu,Dong-Ran Zhu,ShengNan Zhao,Xiao-Chun Wang. The sustainable cyclic process of water molecule dissociation on the boronfunctionalized graphene monovacancy: Firstprinciples study[J]. Applied Surface Science, 2019,498.

5. McGill University; As China rapidly adopts clean energy, use of traditional stoves persists[J]. NewsRx Health \& Science,2019.

6. Hamid M. Pouran. From collapsed coal mines to floating solar farms, why China's new power stations matter[J]. Energy Policy,2018,123.

7. Reza Nadimi,Koji Tokimatsu,Kunio Yoshikawa. Sustainable energy policy options in the presence of quality of life, poverty, and CO 2 emission[J]. Energy Procedia,2017,142.

8. Phebe Asantewaa Owusu,Samuel Asumadu-Sarkodie. A review of renewable energy sources, sustainability issues and climate change mitigation[J]. Cogent Engineering,2016,3(1).

9. Energy; Studies from Tokyo Institute of Technology in the Area of Energy Described (Clean Coproduction of $\mathrm{H}-2$ and power from low rank coal)[J]. Energy Weekly News,2016.

10. Anonymous. Masdar launches Shams 1, world's largest CSP plant[J]. Oil \& Gas News,2013. 